\title{
The Impact of Behavior-Based Strategies on Supply Uncertainty
}

\author{
Pirola Fabiana and Pinto Roberto \\ CELS - Research Center on Logistics and After-Sales Service \\ University of Bergamo \\ Viale Marconi, 5 - 24044 Dalmine, Italy \\ fabiana.pirola, roberto.pinto\} @unibg.it
}

\begin{abstract}
Today's economical environment encompasses a high level of uncertainty, which affects decision makers capability in predicting future events, their occurrence probability and possible decision outcomes. A common way to guard against uncertainty is holding inventory in order to ensuring business continuity and on-time delivery to customer, buffering the effect of the risk. This method belongs to the buffer-oriented techniques that represent only a shield against uncertainty and contribute to raise the overall costs. A more effective way to reduce supply uncertainty is to deeply analyze its sources and try to reduce its occurrence probability adopting behavior-based strategies. A Systems Thinking model, aiming at explaining the logical relationships among different strategies and at analyzing their impact on supply uncertainty and total costs, is presented.
\end{abstract}

Keywords: Supply uncertainty, behavior-based strategy, buffer-based method.

\section{Introduction}

Effectively manage a supply chain has become a complex and challenging task because of today's economical environment, characterized by rapid technological changes, shorter product lifecycles, demanding customers and global competitors. This context encompasses a high level of uncertainty, which affects decision makers capability in predicting future events, their occurrence probability and possible decision outcomes. Davis [5] recognizes three sources of uncertainty in the supply chain: demand, manufacturing process and supply. Demand uncertainty depends on customer orders variability, manufacturing uncertainty is due to internal problems arising during the manufacturing process, while the latter is associated with supplier failure in delivering products as required by customer. This leads to a variability in delivery lead time and then to uncertainty about supply availability. Consequently, disruption in firm production scheduling, increased inventory costs and reduced service level can occur. In their study Boonyathan et al. [1] showed that supply uncertainty is a more significant determinant of organizations performance than demand uncertainty. Therefore, managing supplier uncertainty becomes a relevant factor in developing supply chain strategies. This paper focuses on supply side of the risk and on strategies 
followed to deal with this risk. Common methods employed to manage supply uncertainty are buffer-oriented methods [26] that include holding stocks to reduce the stock-out probability in case of delays in supplier deliveries. Since buffers increase total cost, according to Zsidisin et al. [26], a more effective method to reduce supply uncertainty is to deeply analyze its sources and consequently undertake behaviorbased strategies in order to eliminate or reduce this risk, focusing on supplier process rather than on its outcomes.

Hence, the main research questions are (i) which are the main sources of supply uncertainty, (ii) which are the main behavior-based strategies an organization could undertake to attempt to reduce or eliminate it and (iii) which are the relationships among these strategies, the uncertainty level and the overall costs.

In order to pursue these objectives, the following section provides a literature overview about supply uncertainty, its main sources, buffer-based methods and behavior-based strategies. In section 3, Systems Thinking methodology is introduced and, based on this methodology, in section 4 a model analyzing the relationship among buffer-based methods, behavior-based strategies and supply uncertainty is proposed. The last section concludes the paper with some remarks and indications for further researches.

\section{Literature Overview}

Due to recent increased interest in decision making under uncertainty and risk, Samson et al. [19] stated that there is no general definition for these terms but rather many discipline and context dependent definitions. For the purpose of this paper, we consider risk and uncertainty as two different but related concepts. In particular, according to Willet [19], we define risk as the "objective uncertainty regarding the occurrence of an undesirable event", while the subjective uncertainty "resulting from the imperfection of man's knowledge" is uncertainty. Consequently, considering risk as the occurrence probability of an undesirable event, uncertainty is the greatest when this probability is $1 / 2$ because the decision maker completely does not know which will be the outcome (the undesired event has the same probability of occurring or not). The uncertainty level decreases when the probability increases or decreases and it is null when the probability is 0 or 1 . This paper focuses on supply uncertainty, that, accordingly with the above definitions, is related to supply risk. Referring to Zsidisin [27], supply risk is defined as "the probability of an incident associated with inbound supply from individual supplier failures or the supply market occurring, in which its outcomes result in the inability of the purchasing firm to meet customer demand or cause threats to customer life and safety". In a study about uncertainty in supply chain, Ho et al. [8] stated that supply uncertainty sources are related to complexity, quality and, especially, timeliness of delivered products. In fact, the more complex is a product the more human intervention is required; this increases the errors probability and the time needed to resolve them and can lead to delivery delays. Relating to quality, two different cases can occur: in the first one, defects are detected by the supplier before the shipment so it can quickly repair it; in the second one, the quality problem is identified by the buying firm and a supplier intervention is required in order to repair or substitute the defective product. In both cases, delays in delivery can occur, especially when problems come out at the company's plant. Consequently, 
both complexity and quality can be referred to the time dimension of deliveries that disrupt company's processes and schedules.

A common way to guard against uncertainty is holding inventory to ensuring the continuation of the business and on-time delivery to customer ([2], [5], [10], [26]), buffering the effect of the risk. This method belongs to buffer-oriented techniques, as defined by Zsidisin [26], where buffers represent an outcome-based approach to dealing with risk that attempts to reduce its detrimental effects, rather than decrease its occurrence probability. Apart from representing only a shield against uncertainty and do not attempting to eliminate it, the main drawback of this kind of methods is that they contribute to raise overall costs due to storage space, potential obsolescence and capital investment in inventory. A more effective way to reduce supply uncertainty is to deeply analyze its sources and try to reduce the occurrence probability adopting behavior-based strategies [26]. From a literature review, this kind of strategies can be divided in supplier development and supplier integration [23].

Supplier development is defined by Krause [14] as "any effort by a buying firm to improve a supplier's performance and/or capabilities to meet the buying firm's short and/or long term supply needs" and it can be characterized by different levels of buying firm commitment. Krause identified six main activities: (i) formal supplier evaluation, (ii) visits to the supplier's site by buying firm representatives, (iii) certification programs, (iv) bringing supplier representatives on-site at the buying firm to further enhance interaction, (v) supplier award programs, and (vi) training of supplier's personnel by buying firm representatives. Modi et al. [17] added also capital and equipment investments made from procuring firms in supplier operations and partial supplier acquisition from buying firm. Investing in supplier development, the buying firm may reduce transaction costs [14] and, depending on the investment level, may obtain different rewards [13], such as more responsive suppliers and more certainty and continuity in buyer-seller relationship. Obviously, these investments are non transferable and benefits are unrecoverable if the relationship is prematurely dissolved. So, increasing the investment level increases benefits but increases also the firm dependence on suppliers and then the associated risk.

The second strategy available is supplier integration that leads to increase communication and information sharing between buying firm and its supplier and encompasses ([4] , [23]): (i) joint problem solving, (ii) direct communication between buyer and supplier production schedulers and (iii) integration of information technology. Wilson [25], applying system dynamics methodology to investigate the effect of supply disruption on a 5-echelon supply chain, showed that the impact is less severe in a supply chain with vendor managed inventory system than in a traditional supply chain, characterized by lower integration level. This behavior is due to information sharing because the retailer does not overreact to disruption by placing an excessive order to warehouse, as in the traditional structure (the traditional behavior is also demonstrated in [21]). Moreover, supplier integration practices reduce both transaction and production costs [4]. In fact, increasing the coordination level through goal and information sharing, increases familiarity and trust between the two companies and decreases supplier opportunistic behavior, leading to a reduction in transaction costs; from production cost standpoint, integration with a few number of suppliers allows to take advantage of economies of scale and scope. The main drawbacks of supplier integration are the coordination and inflexibility costs, where the first one arises because the need of coordination can increase response times and human capital requirements, while inflexibility comes up because firm is locked into a partner's 
technology and the supplier is not incentivized to innovate with new product or services [4].

In conclusion, referring to supply uncertainty and risk field, usually qualitative and descriptive studies ([1], [11], [26]) are carried out, especially through surveys and case studies, in order to give some insights into the actual employment of different strategies to deal with risk and their perceived benefits. An effective comparison among these strategies is still missing as well as a model that considers systems complexity to address organizations in strategy selection, based on market and firm characteristics and their evolution along the time. Thus, the aim of this paper is to define factors that favor and hinder these possible investments and identify the impact of these strategies in term of risk, uncertainty and overall costs. In order to analyze these relationships, a model is proposed and discussed in the next sections.

\section{Methodology}

The proposed model is realized using Systems Thinking methodology, that focuses on the way that a system's parts interrelate and how systems work over time and within the context of larger systems. The approach of Systems Thinking is different from the traditional form of analysis. While traditional analysis focuses on separating the parts of what is being studied, Systems Thinking, in contrast, focuses on how the thing being studied interacts with other constituents of the system. This means that instead of isolating smaller and smaller parts of the system, Systems Thinking works by expanding its view to taking into account larger and larger interactions. This broad view can help a decision maker to quickly identify the real causes of issues in organizations and allow to solve the most difficult types of problems. As referred by Senge [20], Systems Thinking discipline aims at seeing interrelationships among system parts rather than linear causal-effect chains and seeing processes of change rather than snapshots. In fact, Systems Thinking methodology is based on causal loops diagram [22]: they can be self-reinforcing (R) or self-correcting (B) and they consist of variables connected by arrows denoting causal influences, describing what would happen if there were a change. In the next section, a model attempting to describe how behavior-based strategies and buffer-based methods impact on supply uncertainty will be proposed, using Systems Thinking methodology.

\section{The Proposed Model}

The supply process involves the coupling made up by a company and its supplier which can be seen as the smallest supply chain entity. For this reason, this model will be developed from a firm point of view, considering the relationship with its main suppliers. Modi et al. [17] showed that knowledge transfer activities, and then supplier development and integration activities, are undertaken by the procuring firm especially with suppliers that satisfy a high percent of buyer requirements. Consequently, behavior based strategies make sense in case of relevant suppliers. A useful way to identify these suppliers may be the Kraljic matrix [12], where items are classified based on strategic importance and on supply risk. Therefore, behavior-based strategies can be addressed to suppliers providing strategic and bottleneck items, namely the ones with high supply risk. 


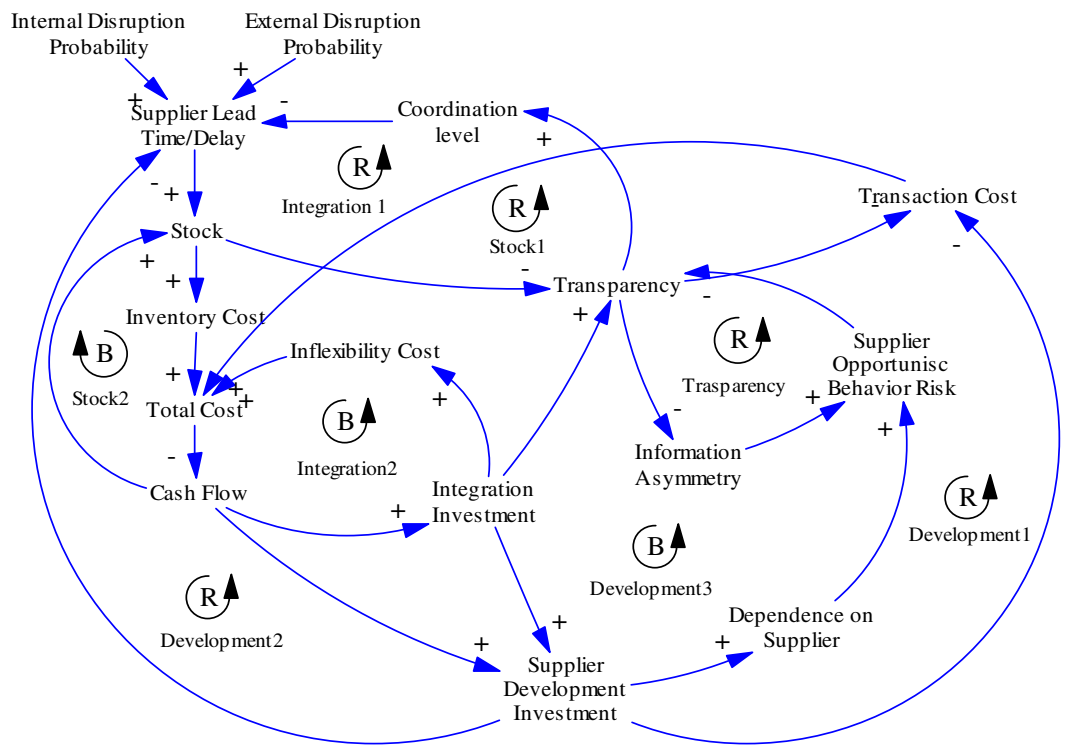

Fig. 1. The proposed model

The model represented in Figure 1 attempts to show the relationships among supplier performance, supply uncertainty, supplier development investments, integration investments, stock holding for a selected supplier. As shown in the literature review section, uncertainty sources depend on product complexity, quality and timeliness. Given that both complexity and quality can be referred to time dimension of deliveries, in this paper supply risk is represented by supplier delivery delay that gives rise to uncertainty because firm does not know exactly when product will be available in the factory plant. Delivery delays depend on supplier internal and external disruption probability. For each available strategy two or more casual loops has been identified, both balancing $(\mathrm{B})$ and reinforcing $(\mathrm{R})$ ones:

- Buffer-based methods ([1], [2], [3], [8], [18], [21], [26]): on the one hand, delays in supplier deliveries increase the quantity stocked by the company, the inventory and total costs, and decrease the cash flow needed to make further capital investment in inventory (Stock2); on the other hand, increase in inventory level decreases the transparency and coordination in the relationship and then even more stocks are taken to buffer uncertainty (Stock1).

- Integration investments ([4], [6], [9], [11], [16], [17], [23], [24], [25]]): cash flow gives the chance to make integration investments; through this kind of investments, a firm can increase transparency and coordination level with its supplier and, hence, decrease delivery delays, buffer size and costs, raising the cash flow needed to make new investment (Integration1); on the contrary, these investments increase the inflexibility costs, raising total costs and decreasing cash flow availability (Integration2). Referring to transparency loop (Transparency), increasing transparency decreases the information asymmetry between buying 
firm and supplier and, consequently, decreases the supplier opportunistic behavior risk and raises the willingness to achieve a more transparent relationship.

- Supplier development investments ([7], [9], [13], [14], [15], [17], [23]): cash flow availability increases the chance to make supplier development investments to reduce both delay probability and transaction cost and achieve a cash flow increase (Development1 and Development2); on the other hand, supplier development investments raise the company dependence on supplier and the supplier opportunistic behavior risk, reducing transparency and increasing delay probability, stock requirement, costs and decreasing cash flow availability (Development3). Additionally, integration degree between the two firms is positively correlated to an effective supplier performance increase.

\section{Conclusion}

Supply risk has become one of the major concern companies are facing. In this paper, methods and strategies to deal with supply risk are identified and classified in bufferbased methods and behavior-based strategies. A Systems Thinking model, aiming at explaining the logical relationships among these different strategies and at analyzing the impact of different investment mix on supply uncertainty reduction and total cost minimization, is presented. The main limitation of this model is that it does not consider all variables influencing supply uncertainty and the adoption of different strategies. Moreover, relationships among variables are given only by a logical point of view. To solve this last problem System Dynamics methodology can be useful, because it is based on Systems Thinking, but takes the additional steps of constructing and testing a computer simulation model.

Thus, the model presented in this paper is only a first step towards a more comprehensive one, where more variable will be considered and a System Dynamics simulation will be carried out. In order to shift the present model in a System Dynamics one, quantitative relationships among variables should be added to allow a computer simulation. Finally, model validation will be realized through simulation and policy analysis in organizations belonging to different industries to evaluate its value in environment with different risk and uncertainty degrees. Since the supply risk level and the strategy impact depend on firm and market characteristics, this will not be a prescriptive model and it will not suggest a standardized firm behavior and a unique strategy mix. At the contrary, based on context characteristics, it will be possible to set the different parameter values and their reactions to strategies in order to understand the system behavior, its sensitivity to initial and boundary conditions.

\section{References}

1. Boonyathan, P., Power, D.: The Impact of Supply Chain Uncertainty on Business Performance and the Role of Supplier and Customer Relationships: Comparison between Product and Service Organizations. In: DSI Mini Conference on Services Management, Pittsburgh, USA (2007)

2. Caputo, M.: Uncertainty, Flexibility and Buffers in the Management of the Firm Operating System. Production Planning and Control 7, 528-538 (1997) 
3. Christopher, M., Lee, H.: Mitigating supply chain risk through improved confidence. International Journal of Physical Distribution \& Logistics Management 34, 388-396 (2004)

4. Das, A., Narasimahn, R., Talluri, S.: Supplier Integration - Finding an Optimal Configuration. Journal of Operations Management 24, 563-582 (2006)

5. Davis, T.: Effective Supply Chain Management. MIT Sloan Management Review 8, 35-46 (1993)

6. Frohlich, M.T., Westbrook, R.: Arcs of integration: an international study of supply chain strategies. Journal of Operations Management 19, 185-200 (2001)

7. Hallikas, J., Karvonen, I., Pulkkinen, U., Virolainen, V.-M., Tuominen, M.: Risk Management Process in Supply Network. International Journal of Production Economics 90, 47-58 (2004)

8. Ho, C.-F., Chi, Y.-P., Tai, Y.-M.: A Structural Approach to Measuring Uncertainty in Supply Chain. International Journal of Electronic Commerce 9(3), 91-114 (2005)

9. Humphreys, P.K., Li, W.L., Chan, L.Y.: The Impact of Supplier Development on BuyerSupplier Performance. Omega 32, 131-143 (2004)

10. Hung, Y.-F., Chang, C.-B.: Determining Safety Stocks for production planning in uncertain manufacturing. International Journal of Production Economics 58, 199-208 (1999)

11. Kaipia, R.: The Effect of Delivery Speed on Supply Chain Planning. International Journal of Logistics: Research \& Applications 11, 123-135 (2008)

12. Kraljic, P.: Purchasing Must Become Supply Management. Harvard Business Review 61, 109-117 (1983)

13. Krause, D.R., Handfiel, R.B., Scannell, T.V.: An Empirical Investigation of Supplier Development: Reactive and Strategic Processes. Journal of Operation Management 17, 39-58 (1998)

14. Krause, D.R.: The Antecedents of Buying Firms' Efforts to Improve Suppliers. Journal of Operation Management 17, 205-224 (1999)

15. Lee, P.K.C., Yeung, A.C.L., Cheng, T.C.E.: Supplier Alliances and Environmental Uncertainty: An Empirical Study (2008) (in Press)

16. Lee, H.L.: Aligning Supply Chain Strategies with Product Uncertainties. California Management Review 44, 105-119 (2002)

17. Modi, S.B., Mabert, V.A.: Supplier Development: Improving Supplier Performance Through Knowledge Transfer. Journal of Operation Management 25, $42-64$ (2006)

18. Molinder, A.: Joint Optimization of Lot-Sizes, Safety Stocks and Safety Lead Times in an MRP System. International Journal of Production Research 35, 983-994 (1997)

19. Samson, S., Reneke, J.A., Wiecek, M.M.: A Review of Different Perspectives on Uncertainty and Risk and an Alternative Modeling Paradigm. Reliability Engineering and System Safety 94, 558-567 (2009)

20. Senge, P.M.: The Fifth Discipline: The Art \& Practice of the Learning Organization, Doubleday, New York (1990), ISBN: 0385472560

21. So, K.C., Zheng, X.: Impact of Supplier Lead Time and Forecast Demand Updating on Retailer's Order Quantity Variability in a Two-Level Supply Chain. International Journal of Production Economics 86, 169-179 (2003)

22. Sterman, J.D.: Business Dynamics: System Thinking and Modeling for a Complex World. McGraw-Hill/Irwin (2003)

23. Wagner, S.M., Johnson, J.L.: Configuring and Managing Strategic Portfolios. Industrial Marketing Management 33, 717-730 (2004) 
24. Wilding, R.: The 3 Ts of Highly Effective Supply Chains. Supply Chain Practice 3, 30-99 (2003)

25. Wilson, M.C.: The Impact of Transportation Disruption on Supply Chain Performance. Transportation Research Part E 43, 295-320 (2005)

26. Zsidisin, G.A., Ellram, E.L.: An Agency Theory Investigation of Supply Risk Management. Journal of Supply Chain Management 39, 15-27 (2003)

27. Zsidisin, G.A.: A Grounded Definition of Supply Risk. Journal of Purchasing \& Supply Management 9, 217-224 (2003) 